\title{
A Cozinha Gaúcha: um resgate dos sabores e saberes da Gastronomia do Rio Grande do Sul
}

\author{
The Gaucha Cuisine: a ransom of flavors and knowledge of Rio Grande do Sul Gastronomy
}

Tainá Bacellar Zaneti

Universidade Federal de Ciências da Saúde de Porto Alegre - UFCSPA - Porto Alegre - Rio Grande do Sul - Brasil

\begin{abstract}
Resumo: $O$ contexto atual da alimentação encontra-se em meio a sistemas agroalimentares cada vez mais segmentados, o que põe em risco as tradições relacionadas à alimentação. Ao se conferir à comida e à culinária o status de bem cultural e identitário, elas passam a ser instrumentos de transmissão, de vivência e de valorização das tradições. Este aparente papel estratégico de receitas e produtos típicos para o desenvolvimento regional impulsionou a instituição do decreto № 4868 , Programa RS MAIS GASTRONOMIA/Casa Civil, do Governo do Estado do Rio Grande do Sul com a finalidade de resgatar, pesquisar, catalogar e divulgar os assuntos referentes à gastronomia gaúcha, que atuou de 2011 a 2015. Este artigo deriva de um projeto de pesquisa vinculado a este programa e teve como objetivo verificar o cenário das tradições gastronômicas dos principais grupos étnicos do estado, tendo como recorte para a pesquisa de campo, a região centro sul, composta pelas cidades: Charqueadas, Jaguarão, Pelotas, Piratini, Rio Grande, Santa Vitória do Palmar, Turuçu e Porto Alegre. Para tanto, utilizou-se uma abordagem qualitativa, com pesquisa documental e entrevistas semiestruturadas. Foram realizadas 50 entrevistas com donos de restaurantes, agricultores, representantes de grupos étnicos e agentes do poder público. Os dados foram analisados com auxílio do software NVIVO versão 10. A partir da análise das entrevistas, pode-se inferir que, em meio ao processo de globalização e consumo cotidiano de produtos processados, muitas receitas, técnicas e pratos tradicionais foram se modificando ao longo do tempo pela busca de praticidade e pela dificuldade de adquirir os ingredientes típicos, principalmente no meio urbano, onde se nota uma desconexão na relação produtor-ingredienteconsumidor. No entanto, essas tradições mantêm-se vivas nos núcleos familiares e nas comunidades, preparadas principalmente aos domingos e dias de festa, manifestando, assim, as tradições que compõem a identidade dos grupos.
\end{abstract}

Palavras-chave: Gastronomia. Identidade Regional. Tradição. Receitas típicas.

Abstract: The current context of food is in the midst of agrifood systems increasingly segmented, which endangers the traditions related to food. Given to food and cooking the status of cultural identity, they become instruments of transmission, of experience and of appreciation of the traditions. This apparent strategic role of recipes and typical products for regional development was boosted into the decree No. 4868, which instituted the Program RS MAIS GASTRONOMIA, in Rio Grande do Sul - Brazil, in order to rescue, search, catalog and disseminate the issues relating to the state's cuisine, who served from 2011 to 2015 . This article derives from a research project linked to this program and aimed to check the setting of the gastronomic traditions of the main ethnic groups in the state, with the cutout for the field research the south central region, consisting of the cities: Charqueadas, Jaguarão, Pelotas, Piratini, Rio Grande, Santa Vitória do Palmar, Turuçu and Porto Alegre. Therefore, we used a qualitative approach with documentary research and semi-structured interviews. They were conducted 50 interviews with restaurateurs, farmers, representatives of ethnic groups and public officials. Data were analyzed using NVivo software version 10. From the interviews it appears that, in the midst of globalization and daily consumption of processed foods, many recipes, techniques and traditional dishes have been modified over time by search practicality and the difficulty of acquiring the typical ingredients, especially in urban areas, which notes a disconnect in the producer-consumer relationship ingredient. However, these traditions remain alive in households and 
communities, especially prepared on Sundays and feast days, expressing thus the traditions that make up the groups identity

Keywords: Gastronomy. Regional Identity. Tradition. Typical Recipes

Ágora [ISSN 1982-6737]. Santa Cruz do Sul, v. 18, n. 1, p. 28-42, jan./jun. 2016.

http://online.unisc.br/seer/index.php/agora/index 


\section{Sovando o mate: uma introdução acerca dos} saberes, sabores e identidades culinárias

Tratar de temas alimentares é sempre algo complexo, como lembra Woortman (2013). As constantes e rápidas mudanças no sistema de produção e processamento de alimentos, bem como a globalização das economias, costumes e mercados, inserem as práticas alimentares em um ambiente inconstante, uma vez que "na sociedade complexa urbano-industrial, os processos de transformação são muito rápidos, fazendo com que o indivíduo se reproduza socialmente de forma fragmentada em seu próprio meio" (Barros, 2005, p. 4). As tradições culinárias, neste contexto, se confrontam com a transição, adaptação e ressignificação de ingredientes, utensílios e saberes. A literatura acerca das temáticas de sociologia e antropologia da alimentação aponta que as cozinhas e culinárias de grupos sociais são espaços de observação de culturas, considerando que estas estão em constante movimento.

Ao considerar, então, comida como cultura e, assim, como comunicadora de valores e signos culturais, podemos entender as tradições culinárias como memória social (Amon e Menache, 2008). A memória, de acordo com Barros (2005), pode ser definida como um mecanismo motor e cultural, presente na vida cotidiana dos indivíduos e grupos, sendo depositária dos "valores culturais estruturantes das práticas sociais necessárias ao convívio em grupo". A memória pode ser entendida como alimento para os processos de identidade e identificação dos grupos sociais na contemporaneidade. É esta oposição entre o antigo e o moderno que permite a atualização e ressignificação das tradições. E é sobre essas transições nos espaços alimentares que se trata este artigo.

Ademais, a vasta oferta de alimentos, de informações sobre alimentação e segmentação das cadeias produtivas geram, segundo Fischler (1995), ansiedade no comensal moderno em relação as suas escolhas alimentares. Esta sensação de desconfiança frente os alimentos e o desconhecimento das formas de fabricação dos alimentos e das matérias-primas utilizadas, para o mesmo autor, "gera confusão, uma vez que estimula nos consumidores uma atitude de desconfiança diante da oferta alimentar, muito mais abundante do que nunca" (Contreras, 2005, p.136).

Não obstante, as tendências da alimentação contemporânea, seja pela busca de saúde, por posicionamento político ou pela busca por prazer, convergem na preocupação em conhecer o caminho do alimento, desde sua origem ao processo de produção, buscando certificar-se da qualidade do produto final. Barbosa (2009) elenca quatro principais tendências da alimentação, sendo elas: 1) a medicalização: discurso nutricional e médico no campo da alimentação; 2) a saudabilidade: holística, transcendendo os aspectos nutricionais ao incluir a noção de bem-estar e de energia, bem como as questões ambientais e sociais; 3) a valorização de origem-capacidade de identificação da origem e trajetória de um alimento, que redefine o consumo, transformando-o em uma experiência fundamental para a segurança alimentar das sociedades contemporâneas; 4) e, finalmente a gastronomização: se refere à estetização, ritualização, valorização do sabor e do prazer.

Castañeda (2010), ao analisar as tendências elaboradas por Barbosa, explica que a primeira é central para entender as mudanças no processo produtivo e na valorização de meios tradicionais e artesanais de produção de alimentos, também valorizados pela tendência da cientificação, que considera a doença como fruto do processo de produção e industrialização dos alimentos. Por outro lado, Castañeda (2010) indica que a valorização de origem e gastronomização remetem a mudanças de atitudes em relação ao comer e à alimentação. Assim, segundo o autor, a gastronomização incentiva a melhoria do sabor, que é um dos argumentos em favor dos produtos da agricultura orgânica, contribuindo, assim, para a valorização de origem.

Deve-se compreender que essas tendências de valorização da origem e (re) valorização das tradições culinárias acompanham o movimento dual 
da atualidade frente ao processo de globalização de uniformização e individualismo e globalização e regionalização (lanni, 1997). Nesta perspectiva, a literatura acerca de alimentação tradicional aponta que a perda das culturas locais e tradicionais ocasiona um movimento de exaltação do nacionalismo e da cultura individual de cada grupo, podendo se refletir no sistema de preferência do consumo desses grupos, ocasionando um processo de valorização de produtos tradicionais. Poulain (2004) explica que cada vez que as tradições são postas em perigo, a cozinha local se mostra resiliente. Da mesma forma, Zuin e Zuin (2008) entendem que quanto mais globalizadas as culturas ficam, mais regionais elas se tornam, pois o consumo do alimento tradicional passa por uma afirmação da identidade do indivíduo.

É diante deste cenário emerge a questão deste estudo na tentativa de compreender como o cenário da alimentação e da gastronomia na globalização contemporânea convivem com as tradições e a identidade alimentar local e suas relações sociais, culturais e econômicas. Ao levar em conta 0 enfoque multidimensional do estudo, observou-se a necessidade de ressaltar, também, o approach territorial para melhor compreender as regiões estudadas. Para tanto, parte-se do pressuposto, elaborado por Silva e Etges (2012), de que há interface entre o meio rural e o segmento gastronômico, no processo da formação de identidade territorial.

Assim, o resgate cultural da identidade local funciona como mecanismo para o desenvolvimento territorial da região promove, por um lado a autonomia dos meios de produção e saber fazer, (re) valorização cultural e o uso consciente dos recursos naturais e, por outro, a interação em redes, a gestão participativa e a cooperação entre os atores locais, poder público, instituições e mercados. Estes fatores associados permitem a inserção fortalecida destes atores no mercado com espaços econômicos que compreendam suas particularidades, menor índice de falhas e maior coesão social (Schneider, 2004; Ferrari, 2011).
Esta discussão pode ser observados na contemporaneidade gaúcha. No Rio Grande do Sul, como em grande parte de nosso país, apesar do reconhecimento da importância cultural da alimentação ainda ser incipiente, muitas ações relacionadas a (re) valorização territorial e cultural por meio das tradições alimentares e culinárias estão sendo feitas. $O$ aparente papel estratégico de receitas tradicionais e produtos típicos impulsionou o decreto no 4868, que instituiu o Programa RS MAIS GASTRONOMIA/Casa Civil, do Governo do Estado do Rio Grande do Sul, com a finalidade de resgatar, pesquisar, catalogar e divulgar os assuntos referentes à gastronomia gaúcha. Este GT, que atuou no período entre 2011 a 2015, foi a primeira política pública do país que fomenta a valorização da gastronomia regional brasileira.

Para tanto, o GT realizava ações para aproximar e criar redes entre os produtores, os chefs e restaurantes e a comunidade para fomentar a conservação e novos espaços para os produtos e receitas tradicionais, como: a) reunião-almoço mensal, com destaque deum produto emblemático, com os produtores, empresários e chefs; b) participação nos festivais realizados pelas comunidades, no intuito de divulgar os eventos, resgatar as tradições e aproximar e promover a gastronomia tanto como cultura, quanto como potencial mercado.

Nestes eventos, o GT além de estandes, organizava cozinhas-show para aulas com chefs e palestras sobre a gastronomia e os mercados dos produtos destaque. Concomitantemente, eram realizadas pesquisas para a) identificação das origens das diferentes práticas alimentares que ocorrem no estado do Rio Grande do Sul, b) verificação da importância das diferentes etnias e suas influências na culinária gaúcha; e c) do registro e documentação dos aspectos relativos à diversidade alimentar do Estado e sua relação com os aspectos culturais, sociais e econômicos das diferentes regiões e comunidades e destas na formação do estado.

Assim, o grupo de trabalho referente ao programa realizou mais de 700 entrevistas com 
indivíduos de diversas etnias e regiões do estado em 40 municípios. Com o intuito de obter maior abrangência de munícipios e com o objetivo de formar um banco de dados sobre a cultura alimentar do RS, o grupo de trabalho elaborou, juntamente a Fundação de Apoio a Pesquisa do Rio Grande do Sul FAPERGS, um edital de participação e apoio a pesquisa para quatro universidades gaúchas para a pesquisa da cultura e tradição alimentar do RS, em quatro macro regiões do Estado. Este artigo é derivado das pesquisas realizadas com o apoio deste edital e teve como objetivo verificar o cenário das tradições gastronômicas dos principais grupos etnicos do estado, tendo como recorte para a pesquisa de campo, estipulado pelo Programa Mais Gastronomia, a região centro sul, composta pelas cidades: Charqueadas, Jaguarão, Pelotas, Piratini, Rio Grande, Santa Vitória do Palmar, Turuçu e Porto Alegre.

Para melhor visualização do roteiro da pesquisa, foi elaborado um mapa com os pontos pesquisados, como pode ser observado abaixo:

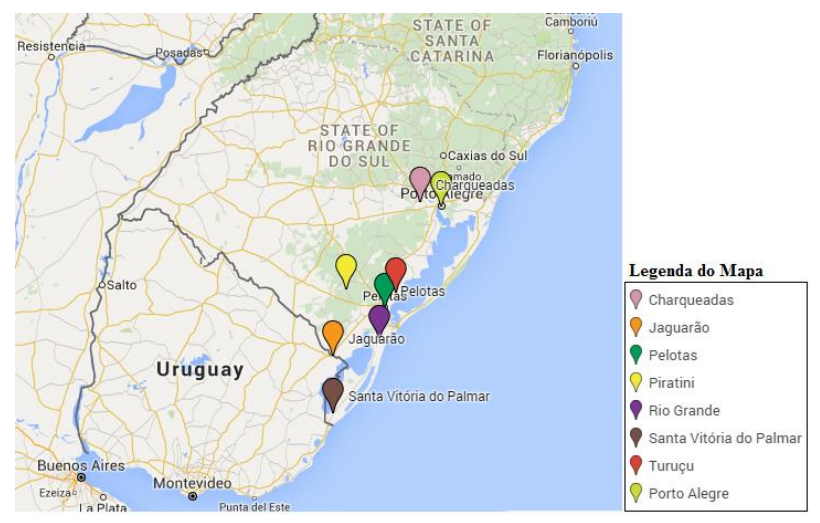

Fonte: elaboração própria.

\subsection{Os percursos metodológicos da pesquisa}

Para alcançar os objetivos propostos neste projeto, além de uma equipe multidisciplinar composta por cinco professores pesquisadores e oito alunos, se fez necessário o uso de diferentes técnicas de investigação passíveis de ser mobilizadas ao longo dos 8 (oito) meses de sua realização, entre maio a dezembro de 2014. A pesquisa foi realizada a partir de um conjunto de técnicas de natureza qualitativa. O levantamento de um conjunto de informações básicas relacionadas aos elementos constitutivos da identidade local contribuiu para uma melhor contextualização dos casos estudados e para a estruturação de um banco de dados compartilhado entre toda a equipe.

A compreensão do cenário da alimentação e da gastronomia na contemporaneidade globalizada envolve fundamentalmente a realização de entrevistas com diferentes atores envolvidos na formação das identidades locais de cada cidade. Para mensurar e identificar a comunidade bem como os atores-chave dos municípios foi realizada pesquisa exploratória sobre os dados demográficos, socioeconômicos e sobre a história e cultura de cada cidade. Em termos de pesquisa documental faz-se necessário uma análise de livros de cozinha e receitas das diferentes etnias dos moradores da região.

Assim, a pesquisa seguiu quatro principais etapas. Primeiramente, foi realizada uma revisão de literatura acerca de assuntos relacionados a antropologia, sociologia e história da alimentação e exploração dos dados e história das cidades. Após identificar o estado da arte dos assuntos relacionados a alimentação e, principalmente, a cultura, tradição e memória alimentar, e de delinear o perfil socioeconomico e histórioco das cidades a serem estudadas, foi desenvolvido o instrumento de pesquisa, que resultou em um roteiro de entrevista semi-estruturada, com dez perguntas que investigou desde o perfil socioeconomico e étnico do entrevistado até seu hábitos alimentares e tradições culinárias de sua família. A Terceira etapa da pesquisa foi a ida a campo, aplicação do instrumento de pesquisa com realização das entrevistas semiestruturadas. Foram realizadas 50 entrevistas com atores-chave como donos de restaurantes tradicionais, agricultores familiares, representantes de grupos étnicos, idosos e agentes do poder público. $\mathrm{Na}$ quarta etapa, após a transcrição das entrevistas, foi realizada a categorização das falas dos entrevistados. A análise dos dados com auxilio do software NVivo versão 10 . As falas foram 
categorizadas em categorias de análise (nós) e, posteriormente, analisadas.

Por fim, foi feita a redação do relatório geral do projeto, que forneceu os subsídios para a

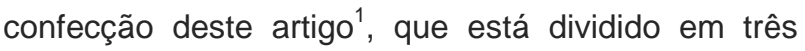
partes, além desta introdução. Na primeira parte, discorreu-se sobre o estado do Rio Grande do Sul, principalmente sobre a formação de sua cultura e gastronomia. A segunda parte se debruçou sobre a análise dos dados da pesquisa. Optou-se por falar de cada cidade em separado, para evitar generalizações e respeitar a trajetória de cada local. Ao final, nas considerações finais da pesquisa, lançou-se um olhar geral sobre o mosaico cultural da região estudada.

\section{O contexto da gastronomia gaúcha: uma identidade formada pela diversidade cultural}

O Rio Grande do Sul é o estado mais ao sul dos 27 estados da federação brasileira. Possui uma área de $281.748 \mathrm{~km}^{2}$, que comporta 497 munícipios e 11,21 milhões de habitantes (IBGE, 2016). O estado é comumente retratado pelas paisagens do bioma pampa, imaginário que se deve ao romance "O Gaúcho", escrito por José de Alencar, em 1870, que ocupa $41,32 \%$ do território do estado, e pela figura do gaúcho, pilchado, com suas botas, bombacha, lenço vermelho e chapéu.

Apesar disso, o Rio Grande do Sul é marcado por sua diversidade de paisagens e etnias, aproveitando estas particularidades para impulsionar sua economia que se baseia, atualmente, na agricultura (soja, trigo, arroz e milho), na pecuária e na indústria (de couro e calçados, alimentícia, têxtil, madeireira, metalúrgica e química) (IBGE, 2016). O território sul rio-grandense foi palco para grandes momentos históricos que moldaram seu povo, história e cultura. Este fato pode ser percebido pela heterogeneidade de sua população. Durante a

\footnotetext{
1 Vale ressaltar que o enfoque deste artigo não é fazer um discussão teórica acerca das temáticas de cultura, alimentação, tradição e modernidade, e nem discorrer sobre conceitos como etinias e grupos sociais, apesar de compreendermos a relevância desses arcabouços para a compreenção científica da realidade empírica sobre a qual nos debruçamos. O enfoque aqui será em contextualizar a culinária gaúcha sob o olhar de alguns autores e apresentar os dados da pesquisa em questão.
}

pesquisa documental e exploratória foi possível identificar que a população do estado é, em grande parte, formada por descendentes de portugueses, alemães, italianos, africanos e indígenas e em pequena parte por espanhóis, poloneses e franceses, dentre outros imigrantes.

Primeiramente habitado por indígenas, com destaque para os Guarani, Pampeanos e Gês (Kaigang) (Moure, 1994), a história do estado, marcada por movimentos migratórios, o configurou como um território de múltiplas etnias que hoje configuram o povo gaúcho. Fatos como a ocupação dos colonizadores espanhóis e portugueses a partir do século $\mathrm{XVI}$, a dominação e extirpação indígena, instalação dos jesuítas e o desenvolvimento da pecuária, o movimento separatista da Guerra dos Farrapos, ocorrida entre 1835 a 1845, e, finalmente, a imigração europeia no final do século XIX dos povos alemães, italianos, pomeranos e poloneses, configuraram não só um cenário social multicultural, mas também, um caldeirão gastronômico pautado no saber tradicional dos diferentes povos, no hibridismo cultural e na adaptação da alimentação ao dado contexto histórico.

Segundo Marques e Campos (2013), cada etnia deixou suas contribuições para a gastronomia gaúcha. As autoras ressaltam alguns exemplos, como a herança indígena percebida pela utilização da mandioca e de seus produtos, no cozimento dos alimentos, que era realizado na tucuruva (trempe de pedras), no moquém (grelha de varas) utilizado para assar carne ou peixe e, finalmente, o mate, difundido como Chimarrão. As técnicas do churrasco, prato símbolo do estado e destacado como comida de festa por todos os entrevistados foram adaptadas para carne bovina quando da ocupação dos espanhóis que instituíram a criação de gado, principalmente na região dos pampas gaúchos, situado principalmente ao extremo sul do estado e nas regiões fronteiriças com a Argentina e Uruguai.

A cultura do gado e das migrações com as boiadas desenvolveu, também, outro produto emblemático do estado: a carne de charque, que é a carne bovina cortada em mantas, salgada e seca ao 
sol, ingrediente principal do arroz de carreteiro, que também ocupa posição de destaque entre os preparos considerados típicos do estado.

Os imigrantes italianos introduziram as massas recheadas, o galeto al primo canto (frango pequeno assado na brasa), a polenta, o salame, a sopa de capelleti (massa recheada de carnes cozida no caldo de frango) e o vinho. Dos alemães herdou-se o joelho de porco, as cucas, küschimier, as salsichas, os salsichões, preparos a base de batata e as cervejas; e, dos monastérios e portugueses, a produção de doces, principalmente de ovos, feitos na região de Pelotas.

Apesar da influência das diversas etnias ser tão presente na identidade gaúcha, em suas várias regiões e na própria capital Porto Alegre, os hábitos tradicionais de cada uma destas etnias vêm sofrendo um processo de hibridização cultural. Esse processo influencia e é influenciado tanto pela cultura já instalada no Rio Grande do Sul e pelos turistas vindos de outras localidades do Brasil e do mundo, como, também, pelas mudanças econômicas, tecnológicas e sociopolíticas forçando a sua adaptação ao novo contexto e às novas demandas, como relatam Machado e Menasche (2012, p. 7):

"Com o passar dos anos, novas práticas alimentares foram sendo incorporadas ao cotidiano destas famílias, pela convivência e troca com os brasileiros (gaúchos), o que permitiu que hábitos e costumes fossem introduzidos e ressignificados. O chimarrão, hoje muito presente, é o momento em que as famílias se reúnem para conversar e assistir televisão, ou seja, não é mais o preparo da polenta e o rezar o terço que reúne a família. Este momento foi substituído, em parte, pela televisão. O churrasco, atualmente considerado nas festas da comunidade o prato principal, é comida valorizada pelas famílias."

Há também um importante aspecto simbólico em relação a diminuição do consumo de preparos tradicionais pelas famílias que saíram do campo ou que migraram da atividade de subsistência para a de comercialização, como contam Zanetti e Menasche (2009, p. 9):
"Ao analisar os saberes e práticas alimentares em famílias rurais, em sua maioria descendentes de imigrantes italianos, no município de Maquiné, Rio Grande do Sul, constatou que a polenta, bem como outros alimentos oriundos do milho, como o cuscuz e o pão de milho, foram, no passado, a base da alimentação de inúmeras famílias. Além disso, alguns de seus entrevistados, principalmente os idosos, afirmaram ainda consumir polenta quase que diariamente. Contudo, em famílias rurais que vivenciaram o processo de modernização da agricultura e passaram a cultivar somente produtos para a comercialização, ou em famílias que migraram para centros urbanos e abandonaram o trabalho na agricultura, o consumo de polenta e de outros alimentos à base de milho foi, com frequência, drasticamente reduzido, pois esses alimentos remetem a tempos difíceis que enfrentaram no passado, quando a polenta era um dos únicos alimentos que a família dispunha."

Sobre isso, observa-se que há heterogeneidade de significados para os atores envolvidos com a gastronomia tradicional. Woortman (2007) observa, em suas pesquisas numa colônia alemã no Rio Grande do Sul, que há uma diferença de valorização da gastronomia tradicional entre os mais velhos e os mais jovens. Para os mais velhos, comer o que é produzido em casa é fator de orgulho por terem conseguido produzir, além de considerarem mais seguro e saudável. Para os jovens comer o que é feito em casa é uma fraqueza, revelando o baixo poder aquisitivo para comprar os alimentos, por isso "ocorre o caso da desvalorização do que é "feito em casa", pelo signo de atraso e pobreza que podem evocar" (Woortman, 2007).

A mesma autora afirma que o turismo e a migração tem um papel fundamental para a ressignificação dos alimentos tradicionais, atrelando um aumento de valor simbólico e econômico para os produtos tradicionais, como explica no trecho "As comidas tradicionais sofreram adaptações, devido ao impacto do turismo e da migração para áreas urbanas. É o caso da sofisticação (...) O turismo conduziu a uma ressignificação dos hábitos de consumo de 
comidas tradicionais e conduziu a uma revalorização da comida "étnica"” (Woortman, 2007).

Visto a diversidade de elementos que compõe a cultura culinário do RS, seria simplista afirmar que exista uma única identidade gastronômica gaúcha. Nessa perspectiva, no ano de 2010, foi realizada uma pesquisa pela DCS Comunicação e Segmento Pesquisa em vinte municípios do Estado com uma amostragem de 1,2 mil entrevistas, em 20 cidades do estado para investigar a autopercepção dos gaúchos sobre sua identidade. A pesquisa mostrou que $77 \%$ deles identificou o churrasco como sua comida típica, seguido de 9\% das indicações para o "arroz de carreteiro" (Azevedo, 2010).

Pode-se adicionar a estes dados 0 chimarrão, que, como apontam as pesquisas de Maciel (2004), juntamente com o churrasco, conforma o binômio mais expressivo da identidade alimentar gaúcha, e, nas palavras da autora (2004, p. 45): "chimarrão não é um traço de diferenciação social, ele é ligado à imagem de ruralidade e tradição em oposição à modernidade e ao espaço urbano".

Pode-se perceber neste contexto que há uma relação dual entre a tradição e a modernidade no que tange a cultura alimentar do Rio Grande do Sul. Por um lado, a população mais envelhecida e o turismo buscam fortalecer as tradições, ainda que adaptadas. Por outro, a urbanização, a industrialização e o êxodo rural põe em risco de perpetuidade das culturas locais em detrimento a padronização.

Diante deste cenário apresentado pela revisão bibliográfica ${ }^{2}$, será apresentado a seguir, os dados da pesquisa de campo que, em grande medida, corrobora os elementos citados nesta sessão, porém também aprofunda e traz novos elementos acerca da gastronomia gaúcha.

\footnotetext{
${ }^{2}$ Vale ressaltar a dificuldade em encontrar estudos acerca da gastronomia e identidade culinária do Rio Grande do Sul.
}

\section{A gastronomia gaúcha além do churrasco: os resultados e discussões dos dados da pesquisa}

A fim de melhor caracterizar a identidade cultural e alimentar de todos dos municípios estudados, previamente descritos na introdução, serão feitas as principais observações de cada um deles e, ao final, será feita uma análise geral dos dados obtidos.

\section{a) Santa Vitória do Palmar}

Santa Vitória do Palmar é reconhecida por manter as "tradições gaúchas vivas", como informa um entrevistado "patrão" (presidente) do maior Centro de Tradições Gaúchas - CTG da cidade, que se encontra no bioma Pampa e faz fronteira com o Uruguai. Verificou-se que a alimentação da cidade de Santa Vitória do Palmar perpassa as diversas etnias que constituem o município e se une por meio de elementos comuns como o butiá, a linguiça, a carne e o charque.

O entrevistado "patrão do CTG" contou que a carne bovina tem grande importância para a cidade e para o RS, como um todo, e que, por isso, ela é um elemento essencial da identidade gaúcha. Ele conta que com a inserção da cultura de criação de gado bovino, além do churrasco, outro prato emblemático cultura gaúcho foi criado: o arroz de carreteiro, que era feito pelos boiadeiros nas levas das boiadas. $O$ carreteiro tradicional era feito com arroz e carne de charque, em uma panela de ferro no fogareiro que ficava no centro da roda dos gaúchos. O entrevistado conta que sempre faz o churrasco e o carreteiro em eventos fora do estado e do país para representar a cultura gaúcha.

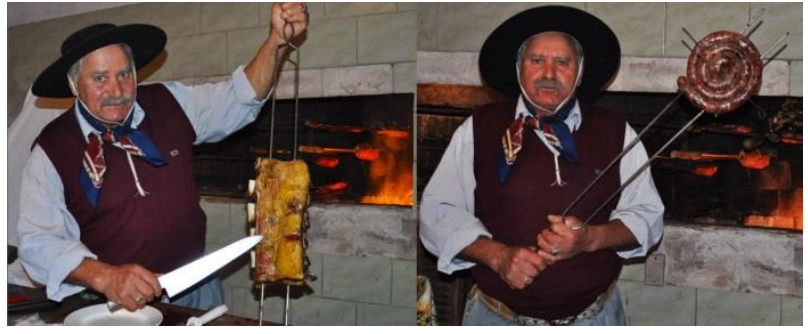


Legenda: Churrasco e linguiça mista preparadas. Fonte: captação dos autores.

\section{- Jaguarão}

Ao pesquisar-se a cidade de Jaguarão percebeu-se que a mesma é uma cidade baseada na sua história, no que diz respeito à alimentação, tendo recebido diversas influências por motivos sociais e econômicos. Dentre as principais descendências étnicas da cidade encontram-se a espanhola, a portuguesa, a africana e a italiana. Apesar de ser uma área originalmente habitada por indígenas, não houve nenhum relato de descendência desses povos. O notável uso da carne bovina, herança da colonização europeia, e a proximidade com a cultura uruguaia demarcam um destaque para a construção cultural do imaginário do gaúcho tradicional, com o consumo do churrasco, além do uso de vestimentas típicas, como as bombachas e da presença do Centro de Tradições Gaúchas.

Os pratos típicos relatados pelos cidadãos entrevistados foram o carreteiro de charque, o feijão e a massa, herança da etnia espanhola que inicialmente povoou a região. Apesar da perda da produção da carne de ovelha, que até os anos 1970, segundo os entrevistados, era a principal atividade econômica da cidade, ocasionada pela substituição desta cultura pela produção de grão, principalmente a soja, a cidade mantem traços da alimentação tradicional, por meio do uso do charque nas receitas e por meio de estabelecimentos centenários, que preservam receitas antigas da cidade. Em relação aos utensílios e processos de produção artesanais, foi comentado que por questões de legislação, muitos preparos tiveram que se adequar as normas da vigilância sanitária, como no caso do tacho de cobre para fazer doces em calda, como comenta uma das entrevistadas: "Eu não posso usar que é o tacho de cobre, que a gentebatia o fondant nele e fazia os cremes nele, que daí a vigilância proibiu. As espátulas de madeira que agora também não pode, tem que ser tudo plástica, né? Ou então de resina".

\section{- Camaquã}

Já no município de Camaquã, foi possível perceber que houve um distanciamento do meio urbano do meio rural. Os entrevistados citaram que antigamente compravam os alimentos direto do produtor rural, plantavam vegetais e criavam os seus animais e, que hoje, eles compram os insumos no mercado, sem se preocupar com a procedência dos mesmos.

No que se refere ao prato típico da região, nenhuma preparação foi citada mais de uma vez, provando assim que não existe uma hegemonia quando se trata desse assunto. Inclusive um dos entrevistados afirmou desconhecer um prato que represente a região. Percebeu-se que alguns insumos e utensílios tidos como tradicionais caíram em desuso, devido à dificuldade de achá-los nos mercados. Outros entrevistados relataram que os utensílios influenciam no sabor, citando principalmente as panelas de ferro que hoje foram substituídas por panelas de alumínio.

\section{- Charqueadas}

Com relação a cidade de Charqueadas, a mesma mostrou-se um tanto heterogênea com relação a gastronomia. Apesar do churrasco ser citado em todas as entrevistas, nenhuma outra receita foi repetida entre os entrevistados. Talvez esse fato se deva a forte presença de imigrantes libaneses, uruguaios e afrodescendentes na região, como apontado pelos próprios entrevistados. Além disso a cidade abriga dois assentamentos da Reforma Agrária em seu território.

Apesar da cidade ter uma forte ligação histórica com as charqueadas, denominação do lugar onde se produzia a carne de charque, o charque não foi citado em nenhuma entrevista como um produto ou preparo típico da cidade. Os entrevistados, quando perguntados sobre o consumo do charque responderam, que apesar dessa ligação, o charque não representa mais cidade, inclusive citaram que o pouco charque que é consumido não é fabricado na cidade e é comprado de forma industrializada nas redes de supermercados da cidade.

\section{- Piratini}


A cidade de Piratini é um município de relevância histórica e política para o estado do Rio Grande do Sul, uma vez que foi capital do estado e centro da Revolução Farroupilha. Dentre as principais etnias que compõe a população atual da cidade destacam-se a portuguesa, a espanhola, a africana, a italiana e a alemã. Alguns entrevistados se intitularam como da etnia gaúcha, afirmando ser uma mistura de indígenas, africanos e europeus. A história da cidade tem como destaque a produção de charque, uma vez que, até o século XIV, era a principal atividade econômica da cidade. Apesar de atualmente o carreteiro de charque ser apontado como o prato típico da cidade, os entrevistados afirmam que não há mais produção expressiva de charque na cidade e o mesmo é comprado em sua forma industrializada nos supermercados da cidade.

Diferentemente de outras cidades pesquisadas, a cidade de Piratini apresentou acesso a grupos quilombolas que afirmaram que muitas das suas tradições alimentares são baseadas na escassez de alimentos provenientes das baixas condições de qualidade de vida e pouco acesso a oportunidades no núcleo social da cidade. Os entrevistados quilombolas afirmam que a base de sua alimentação é a batata doce e o feijão. O entrevistado de descendência africana dono de um dos buffets de festa mais antigos da cidade, que afirmou que seu avô era escravo das fazendas de gado, relatou que sua comida de infância era a canjiquinha de milho com costelinha de porco porém que considera como prato típico da cidade o churrasco e o carreteiro de charque feito na panela de ferro. Pouco destaque foi dado aos doces, mas foi consenso entre os entrevistados que as sobremesas da cidade tem herança portuguesa, dando destaque para a ambrosia, o pudim de leite e os doces de frutas e de abóbora feitos nos tachos de cobre pelas mulheres.

Além disso, os entrevistados comentaram o costume do consumo da broinha de milho e do pão como complementos das refeições. Em relação às ações de preservação e valorização das receitas tradicionais, os entrevistados comentaram que além de alguns poucos restaurantes que fazem comidas tradicionais, principalmente aos domingos, não está sendo feito nenhum tipo de ação para a preservação dessas receitas. Da mesma forma, os entrevistados afirmam que não tem o costume de passar seus saberes tradicionais culinários para seus filhos e netos e também que não tem nenhum tipo de arquivo dessas receitas.

\section{- Rio Grande}

As entrevistas com atores-chaves do município de Rio Grande mostraram que o processo de construção dos saberes constituem uma parte da história gastronômica da cidade, marcada pela forte influência portuguesa. Observou-se a preservação de técnicas de preparo como no caso do peixe na taquara e na produção da cachaça Jurupiga feitas de maneira artesanal, mantendo as tradições ensinadas pelas gerações passadas. Por outro lado, pode-se verificar o oposto, como no caso do restaurante da pesquisa, cujo proprietário está sempre atento as novidades na elaboração dos pratos como a utilização de forno combinado, tecnologia moderna de cocção, mostrando que a cidade convive com estas duas realidades; a tradição e a modernidade.

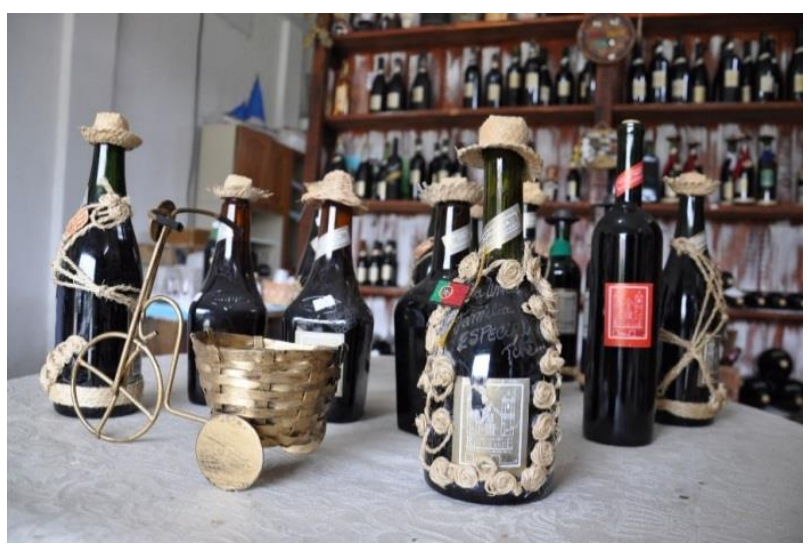

Legenda: Garrafas de Jurupiga enfeitadas com artesanato local. Fonte: captação dos autores

\section{- Pelotas}

Já a cidade de Pelotas, mostrou-se, uma cidade composta por um mosaico de culturas que construíram uma identidade multifacetada. Verificou-se uma expressiva porcentagem de libaneses e japoneses, pomeranos, portugueses e afrodescendentes. Em alguns casos, percebeu-se um esforço para a preservação da identidade étnica, 
cultural e alimentar como no caso da entrevistada pomerana em seu restaurante local. Em contrapartida, os chamados doces de Pelotas, inicialmente de origem tradicionalmente portuguesa, hoje agregam ingredientes modernos, industrializados e de diferentes nacionalidades, apesar de ainda encontrar-se locais que mantém a maneira tradicional de preparo. Como cidade emancipada de Pelotas, cita-se Turuçu que será referida abaixo.

\section{- Turuçu}

Turuçu é um município que se emancipou de Pelotas há 20 anos, estando em fase de construção de sua história e cultura, como afirmam os entrevistados. As principais etnias encontradas na cidade são a pomeranas, a alemã, a italiana, a africana e a portuguesa. Apesar de ser uma área originalmente habitada por indígenas e embora os relatos dos entrevistados apontem que muitos dos saberes aprendidos pelas principais etnias que atualmente habitam a região, não houve nenhum relato nem indicação de possíveis entrevistados de descendência de povos indígenas. Apesar da recente emancipação, a região tem tradição na produção de pequena produção rural, principalmente na cultura de pimentas e morango.

De acordo com o relato dos entrevistados, mesmo antes da emancipação do município a região já era reconhecida nacionalmente como produtora de pimenta, uma vez que comercializa para mercados no estado de São Paulo. Quando a cidade se emancipou, a gestão municipal à época verificou a necessidade de criar uma marca turística para a cidade, no intuito de incentivar o turismo e novos mercados para o município. Assim, foi incorporado a cidade o título de "capital nacional da pimenta", o que impulsionou uma série de atividades para consolidar o título. Como principais medidas, alguns entrevistados, como a ex-prefeita da cidade, destacam a criação da festa anual da pimenta, da festa anual do morango e a construção da Casa da pimenta, um centro de comercialização de produtos a base de pimenta e morango produzidos pelos agricultores locais, como visto na fala da ex-prefeita da cidade:

Turuçu - ex-prefeita da cidade: Os pratos foram surgindo a partir dessa questão do município, da criação daCapital da Pimenta, a partir daí, e outra coisa que caiu na época, já estávamos trabalhando em cima da questão da pimenta, já misturando com geleias, pensandonovas receitas e tudo mais, aí veio a novela Chocolate com Pimenta, que pro municípiocaiu como uma luva, a partir daí começaram a produzir chocolates com pimenta e tudo mais (...)no primeiro ano da nossa administração nós criamos a festa nacional da pimenta vermelha (...) O Município com 3.500 habitantes sem ter uma identidade, nós achavana época que precisava um produto para alavancar.Nós precisávamos criar uma identidade até pra atrair indústriaspara que houvesse uma diversificação de renda, até porque os nossos produtores rurais também plantavam muito fumo

Posteriormente, sob nova gestão da prefeitura, as duas festas que ocorriam separadamente passaram a ocorrer conjuntamente no intuito de fortalecer as duas principais atividades produtivas do município, sendo estas a pimenta e o morango. Apesar destes dois produtos serem destacados como principais peças para a construção da identidade da cidade, estes ingredientes não foram indicados como parte dos hábitos alimentares dos entrevistados, que destacam o churrasco e a salada de batata seca como os principais preparos da cidade. Os entrevistados salientam também que no dia-a-dia, os principais elementos da alimentação são o arroz, o feijão, a carne e algumas hortaliças. Foi dado destaque, também, para o uso da carne de porco e do milho. Em relação aos preparos típicos de cada etnia, pouco destaque foi dado a receitas tradicionais, tendo o churrasco como prato destacado servido em dias festivos, como observado na fala de uma das entrevistadas, "a batata e o próprio churrasco (...)".

Apesar de não ter havido nenhum destaque para um prato tradicional, foi consenso entre os entrevistados o antigo uso da salmoura para temperar 
a carne do churrasco, que era executada na noite anterior ao assado da carne. Os entrevistados afirmaram, porém, que em razão da busca por praticidade e pelo fato da carne atualmente ser conservada na geladeira, essa prática não é mais utilizada. Pode-se inferir que Turuçu está em processo de construção de sua identidade com o apelo à gastronomia e ao turismo pela produção e beneficiamento da pimenta e do morango, porém não aprresenta elementos de tradição culinária ou de meio de fortalecimento e valorização dos saberes gastronômicos dos diferentes povos que compõe a cidade.

\section{- Porto Alegre}

Na cidade de Porto Alegre foram realizadas entrevistas com atores chave de etnias diferentes englobando as etnias Portuguesa, Italiana, Judia, Alemã, Polonesa, Libanesa e ainda a região das ilhas e a região rural que caracterizam a capital gaúcha.

A cidade de Porto Alegre, conta com 81 bairros oficiais e uma população de 1,5 milhões de pessoas cujo gênero feminino se sobressai. O mosaico de múltiplas expressões, variadas faces e origens étnicas, religiosas e linguísticas, faz de Porto Alegre, uma capital cosmopolita e multicultural. Antes habitada por indígenas Guaranis, Charruas, Minuanos e Tapes, a cidade de Porto Alegre foi fundada em 26 de março de 1772 com a criação da Freguesia de São Francisco do Porto dos Casais e um ano depois alterada para Nossa Senhora da Madre de Deus de Porto Alegre.

Seu povoamento, contudo, começou em 1752 com a chegada de 60 casais portugueses açorianos trazidos por meio do Tratado de Madri para se instalarem nas Missões, que estava sendo entregue ao governo português em troca da Colônia de Sacramento. A demarcação dessas terras demorou e os açorianos permaneceram no então chamado Porto de Viamão, primeira denominação de Porto Alegre. Em 24 de julho de 1773, Porto Alegre se tornou a capital da capitania e a partir de 1824 começou a receber imigrantes de todo o mundo, em particular Alemães, Italianos, Espanhóis, Africanos, Poloneses, Judeus e Libaneses.

O Mercado Público se caracteriza como um centro de compras que reúne especiarias requintadas e artigos populares no mesmo espaço. Deixou de ser apenas um ponto de abastecimento e tornou-se uma parada turística e espaço da cidadania na cidade.

Em 1844, no antigo Largo do Paraíso, conhecido hoje como praça $\mathrm{XV}$, foi construído um espaço para abrigar diversos quitandeiros em formato de um mercado livre. Em 1869 foi inaugurado um novo prédio que abriga o atual mercado público. Em 1912 foi construído o segundo pavimento, arquitetura preservada até hoje. Passados momentos difíceis com enchentes e incêndios, o prédio foi tombado em 1979 e conta com 111 estabelecimentos atuando como expressão cultural e comunitária, oferecendo diversos produtos regionais, naturais e especiarias, muito procurado por diversos setores da gastronomia. É patrimônio histórico e cultural de Porto Alegre, equilibrando o tradicional e o moderno e preservando uma prática humanizada de afetividade nas relações entre cliente e vendedor.

Além do Mercado Público também percebeuse 0 interesse de muitas pessoas da capital que buscam por lazer e novas experiências com o turismo rural que tem propiciado um encontro ao caseiro, ao antigo. Porto Alegre é a segunda capital com maior área rural, por conta disso, a rota turística "Caminhos Rurais" reserva um espaço de natureza viva, com áreas produtivas e de preservação ambiental e biológica. Região de estâncias do século XIX é hoje ocupada por pequenas propriedades de expressiva agricultura familiar e agroecológica que preservam a paisagem e o modo de vida tipicamente rural e gaúcho e buscam a sustentabilidade econômica, ambiental, cultural e social por meio do turismo. A ideia de aliar a atividade turística ás propriedades rurais nasceu em 1990, mas só em 2005 o projeto tomou corpo a partir de um inventário, assim a rota foi lançada oficialmente como produto turístico.

Com relação a gastronomia polonesa entrevistou-se a dona de um restaurante polonês 
aonde a mesma cita que as receitas mais emblemáticas de sua família não sofreram alterações apenas que antigamente eram feitas para alimentar a família e hoje são feitas comercialmente. Diferentemente a entrevistada de origem portuguesa e dona de um restaurante português fala sobre as alterações sofridas nas receitas de família.

Um caso foi o preparo do doce "toucinho do céu que passou a ser feito com castanha do para ao invés de amêndoas como na receita original. Também fala sobre o prato "bacalhau as natas", que sofreu alteração, pois, em Portugal se utiliza "pão ralado" (farinha de rosca) e aqui no Brasil passou a usar o queijo ralado. Apesar das mudanças de ingredientes o restaurante mantém suas características étnicas. Já outro entrevistado de etnia Italiana/Portuguesa/ Suíça/Africana/Alemã que gerencia o restaurante fundado por seu pai onde a predominância e preferencia pelos pratos italianos e portugueses eram frequentes, foi dando espaço ao churrasco e grelhados, como maneira de sobreviver comercialmente.

Na região das ilhas, o entrevistado local, que é líder da associação dos pescadores, se identificou o peixe na taquara como prato representativo seu e do local, bem como o espetinho de peixe. O mesmo citou que várias mudanças ocorreram principalmente em função da poluição das águas que alterou principalmente o tipo de peixe pescado.

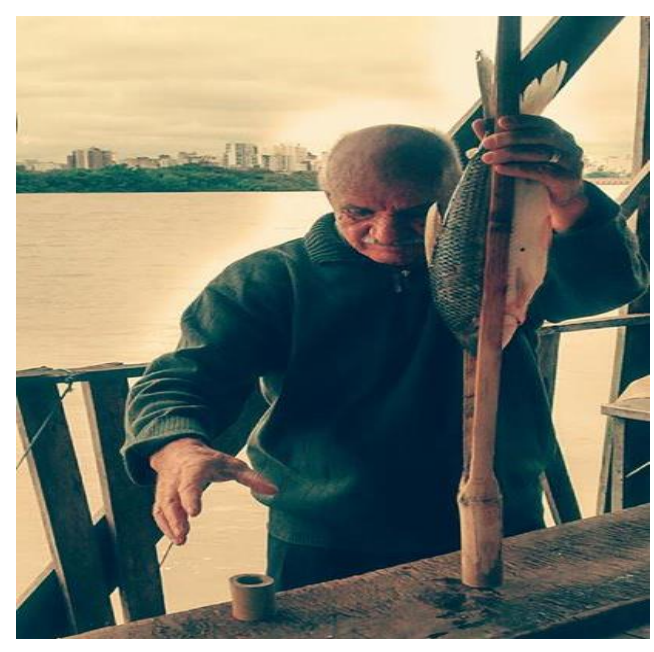

Legenda: Morador e pescador da llha da Pintada, preparando o tradicional peixe na Taquara. Fonte: captação dos autores

\section{0 mosaico gastronômico gaúcho: algumas considerações finais sobre a gastronomia rio- grandense}

Este artigo teve como objetivo verificar o cenário das tradições gastronômicas dos principais grupos étnicos do estado. A partir das entrevistas inferiu-se que, em meio ao processo de globalização e consumo cotidiano de produtos processados, muitas receitas, técnicas e pratos tradicionais foram se modificando ao longo do tempo pela busca de praticidade, pela dificuldade de adquirir os ingredientes típicos, principalmente no meio urbano, onde se nota uma desconexão na relação produtoringrediente-consumidor. No entanto, essas tradições mantêm-se vivas nos núcleos familiares e nas comunidades, preparadas principalmente aos domingos e dias de festa, manifestando, assim, os traços étnicos que compõem a identidade dos grupos.

Além disso, observa-se que os preparos étnicos não estão isolados, apresentado forte ligação com a culinária típica do estado. Assim, o churrasco e o arroz de carreteiro caracterizam-se como os pratos mais apreciados em todas as cidades visitadas, representando uma unidade de identidade regional. $\mathrm{Na}$ aproximação com as narrativas que se constituem como objeto desse estudo, verificou-se que, apesar da celebração das tradições ainda resistirem, as receitas, saberes e modos de preparo não estão sendo transmitidos para as novas gerações. Notou-se também que, na intenção de fortalecer a identidade e cultura local, frente ao progressivo distanciamento das tradições e do meio rural, há esforço do poder público em fomentar redes de comercialização direta entre produtores e consumidores e festivais de produtos e preparos típicos.

Observou-se, também, que os preparos étnicos não estão isolados, apresentado forte ligação com a culinária típica do estado. Assim, o churrasco e o arroz de carreteiro caracterizam-se como os pratos mais apreciados em todas as cidades visitadas, representando uma unidade de identidade regional. $\mathrm{Na}$ aproximação com as narrativas que se constituem 
como objeto desse estudo, verificou-se que, apesar da celebração das tradições ainda resistirem, as receitas, saberes e modos de preparo não estão sendo transmitidos para as novas gerações. Notou-se também que, na intenção de fortalecer a identidade e cultura local, frente ao progressivo distanciamento das tradições e do meio rural, há esforço do poder público em fomentar redes de comercialização direta entre produtores e consumidores e festivais de produtos e preparos típicos.

\section{Referências}

ALMEIDA, C. S. de. A representação juvenil do desenvolvimento regional: estudo de caso em Santa Cruz do Sul/RS. Dissertação (Mestrado) Universidade de Santa Cruz do Sul, 2008.

AMON, D. e MENASCHE, R. Comida como narrativa da memória social. Sociedade e Cultura: revista de pesquisas e debates em Ciências Sociais. Goiânia: UFG/FCS, ano 2008, v. 11, n.1, p. 13-21, 1998.

AZEVEDO, G. Cara a cara com o gaúcho. Zero Hora. Porto Alegre, 03/10/2010, p. 26- 27.

BARROS, J. M. CULTURA, MEMÓRIA E COMIDA. Resultado do processo de consultoria às equipes responsáveis pelo processo de registro dos bens imateriais Queijo do Serro e Queijo da Canastra no IEPHA/MG (Contrato 039/02). 2005. Disponível em: http://transversalconsultoria.com.br/pdfs/tx_11.pdf

BARBOSA, L. Tendências da alimentação contemporânea. In: PINTO, Michele de Lavra; PACHECO, Jane K. (Org.). Juventude, consumo e educação 2. Porto Alegre: ESPM, 2009. p. 15-64.

BRAGA, V. Cultura Alimentar: Contribuições da antropologia alimentar. Saúde em Revista. Rio de Janeiro, 2004.

CANCLINI, N. G. Consumidores e cidadãos. Conflitos multiculturais da globalização. Rio de Janeiro: Ed. UFRJ, 2003.

CASTANEDA, M. Ambientalização e politização do consumo as práticas de compra de orgânicos. Caderno CRH. Salvador, v. 25, n. 64, p. 147-60, 2012.

CONTRERAS, H. (2005) Patrimônio e globalização: o caso das culturas alimentares. Em A. Canesqui e R. Garcia (Orgs.), Antropologia e nutrição: um diálogo possível (pp. 145-159). Rio de Janeiro: Fiocruz.

DINIZ, J. D. A. S.; OLIVEIRA, M. N. S.; ELS, R. H. V.; WEHRMANN, M. E. S. F.; SOUZA, J. S. A. Avaliação da metodologia pesquisa-ação enquanto suporte para projetos de extensão universitária em comunidades rurais. In: 48 Congresso da Sociedade Brasileira de Economia, Administração e Sociologia Rural (SOBER), 2010, Campo Grande. Anais do 48 Congresso da Sociedade Brasileira de Economia, Administração e Sociologia Rural (SOBER), 2010.

FERRARI, D. L. Cadeias Agroalimentares Curtas: a construção social de mercados de qualidade pelos agricultores familiares em Santa Catarina. $334 \mathrm{f}$. 2011. Tese (Doutorado em Desenvolvimento Rural) Universidade Federal do Rio Grande do Sul, Porto Alegre, 2011.SILVA, R.N; ETGES, E. V. Do campo à mesa: reflexões sobre agricultura familiar e gastronomia REDES - Rev. Des. Regional, Santa Cruz do Sul, v. 17, n. 3, p. 142 - 153, set/dez 2012.

Movimento Slow Food O Movimento. 2007. Disponível em:http://www.slowfoodbrasil.com/slowfood/omovimento. Acesso em 23 de dezembro de 2013.

HALL, S. A identidade cultural na pós-modernidade, DP\&A Ed, Rio de Janeiro, 11a edição, 102 p., tradução: Tomaz Tadeu da Silva e Guacira Lopes Louro, 2006.

FERNÁNDEZ-ARMESTO, F. Comida: uma história. Rio de Janeiro: Record. 2004.

MACHADO, C. J. B; MENASCHE, R. Comida e Identidade: histórias, saberes e práticas alimentares entre colonos descendentes de imigrantes italianos. Encontro das Redes Rurais, GT 04 - Cultura e Comunicação no Mundo Rural, 2012.

MACIEL, M. E. Cultura e alimentação ou o que tem a ver os macaquinhos de Koshima com Brillat-Savarin Horiz antropol. 7(16):145-56, 2001.

MACIEL, M. E; GOMBERG, E (Org.). Temas em cultura e alimentação. Aracaju: Editora da Universidade Federal de Sergipe: Fundação Oviêdo Teixeira, 116 p. 2007.

MARQUES, L. A. B; CAMPOS, S. Um pouco da história da culinária do Rio Grande do Sul. disponível em: http://www.mtg.org.br/gastronomia.html - Por Lílian Argentina Braga Marques e Sônia Campos Folcloristas. Acesso em 12 de dezembro de 2013.

MINASSE, M.H.S.G.G., et al. Os lugares da Tradição e da Inovação na Culinária Regional. Revista Ateliê Geográfico- UFGO, v.6, no 3 (Ed.especial) out.2012.

MONTANARI, M. O mundo na Cozinha: História, identidade e trocas. (Tradução Valéria Pereira da Silva). São Paulo: Estação Liberdade SENAC, 2009.

PECCINI, R. História e Cultura da Alimentação: A Galeteria Peccini e o patrimônio de Caxias do Sul (1950 - 1970). Dissertação (Mestrado) Universidade de Caxias do Sul, Programa de pósgraduação em Turismo, 2010. 
POULAIN, J. P; Sociologias da Alimentação. Ed. UFSC (Série Nutrição). Florianópolis, 2004.

SCARPO, P.S. Imigrantes Italianos na Serra do Nordeste do Rio Grande do Sul. EST Edições, Porto Alegre, 2011.

SCHNEIDER, S. A abordagem Territorial do Desenvolvimento Rural e suas Articulações Externas. Sociologias, Porto Alegre, n. 11, p. 88-125, jan./jun. 2004.

SILVA, R. do N.; ETGES, V. E. Do campo à mesa: reflexões sobre agricultura familiar e gastronomia. In: REDES - Revista do Desenvolvimento Regional. Santa Cruz do Sul, v.17, n. 3, p. 142-153, set./dez. 2012.

VALAGÃO, M.M. Tradição e Inovação alimentar: dos recursos silvestres aos itinerários turísticos. Alcácer do Sal: Colibri/INIAP, 2009.

WOORTMANN. E. F. Padrões tradicionais e modernização: comida e trabalho entre camponeses Teuto-brasileiros. In: MENASCHE, R. (Org.) A agricultura familiar à mesa: saberes e práticas da alimentação no Vale do Taquari. Porto Alegre: Ed. UFRGS, 2007. Cap. 10, p. 177-196.

ZANETTI, C; MENASCHE, R. Agricultores familiares, ontem e hoje: uma análise a partir da alimentação. VI Jornadas Interdisciplinarias de Estudios Agrarios y Agroindustriales. Buenos Aires, 2009.

ZANETI, T. B. Das panelas das nossas avós aos restaurantes de alta gastronomia: os processos sociais de valorização de produtos agroalimentares tradicionais 183 p.: il. Dissertação de Mestrado (M) Universidade de Brasília/Faculdade de Agronomia e Medicina Veterinária, Brasília, 2012.

ZUIN, L.F.S.; ZUIN, P.B. Extensão Rural: produção de alimentos tradicionais. Aparecida: Idéias \& Letras, 2008. 